\title{
Comamonas denitrificans sp. nov., an efficient denitrifying bacterium isolated from activated sludge
}

Department of

Biotechnology, Royal

Institute of Technology,

KTH, S-100 44 Stockholm,

Sweden

\author{
Lena Gumaelius, $†$ Gunnar Magnusson, $†$ Bertil Pettersson \\ and Gunnel Dalhammar
}

\author{
Author for correspondence: Gunnel Dalhammar. Tel: +46879087 75. Fax: +468 7909306. \\ e-mail: Gunnel@biochem.kth.se
}

Keywords: Comamonas denitrificans, denitrification, 16S rRNA, phylogeny, activated sludge

\section{INTRODUCTION}

Denitrification is a major process in the global nitrogen cycle. During recent decades this process has been used as a method for biological nitrogen removal in wastewater treatment. This is to prevent eutrophication in the recipient [SNV (Svenska Naturvårdsverket, Swedish Agency for Environmental Protection), 1997]. The ability to denitrify is considered to be a common property in the bacterial flora of activated sludge,

†These authors contributed equally to this work.

The GenBank accession numbers for the 16S rRNA gene sequences of strains $110,123^{\top}, 2.99 \mathrm{~g}, 5.38 \mathrm{~g}$ and P17 are AF233876, AF233877, AF233878, AF233879 and AF233880, respectively. though it is not yet clear what proportion of the bacterial flora possess this quality. It has been suggested that $10-70 \%$ of the cultivable heterotrophic flora establish denitrifying properties (Hallin et al., 1996; Lemmer et al., 1994; von Schmider \& Ottow, 1986). In the literature, little effort has been put into the question of whether a large number of different species perform the bulk of the denitrification or if a low number of efficient denitrifiers are important for the overall process. One hypothesis is that a restricted number of bacterial species perform the bulk of the denitrification in wastewater treatment, using biological nitrogen removal (Magnusson et al., 1998).

The overall aim of this study was to identify and characterize a relevant biomarker for denitrification in 
Table 1. Physiological characters and phenotypic tests for denitrifying strains and Comamonas terrigena

All strains were sensitive to chloramphenicol $(30 \mu \mathrm{g})$, erythromycin $(15 \mu \mathrm{g})$ and streptomycin $(30 \mu \mathrm{g})$ and showed a negative reaction for mannoic acid $\gamma$-lactone, L-arabinose, D-xylose, D-galactose, maltose, D-cellobiose, D-trehalose, palatinose, sucrose, $\mathrm{D}$-lactose, melibiose, lactulose, $\beta$-gentiobiose, D-melezitose, L-raffinose, inosine, adonitol, meso-inositol, D-arabitol, glycerol, maltitol, D-sorbitol, dulcitol, L-sorbose, 2-deoxy-D-ribose, L-rhamnose, D-fucose, L-fucose, D-tagatose, D-amygdalin, arbutin, methyl- $\beta$-D-galactopyranoside, 5-keto-D-gluconate, D-gluconate, $6-O$ - $\alpha$-D-galactopyranosyl-D-gluconic acid, D-galactonic acid $\gamma$-lactone, D-ribose, L-xylose, D-glucose, D-mannose, L-arabitol, meso-erythritol, D-mannitol, xylitol, D-fructose, 6-deoxy-Dgalactose, $2^{\prime}$-deoxyinosine, inulin, methyl- $\alpha$-D-mannopyranoside, methyl- $\alpha$-D-xylopyranoside, methyl- $\alpha$-D-galactopyranoside, starch, D-galacturonate, D-arabinose, D-turanose, D-glucuronolactone, glycogen, D-lyxose, $N$-acetyl-D-glucosamine, maltose, D-gluconate, caprate, adipate, maleate, phenylacetate, gelatin, $p$-nitrophenyl- $\beta$-D-galactopyranoside, L-tryptophan and arabic acid. $\mathrm{S}$, Sensitive; R, resistant; +, significant reaction calculated as 3 standard deviations; $(+)$, reaction calculated as $2-3$ standard deviations.

\begin{tabular}{|c|c|c|c|c|c|c|}
\hline Character & 110 & $123^{\mathrm{T}}$ & $5.38 \mathrm{~g}$ & $2.99 \mathrm{~g}$ & P17 & Comamonas terrigena \\
\hline Nitrate reduced to $\mathrm{N}_{2}$ & + & + & + & + & + & - \\
\hline Pigment producer & - & - & - & - & + & - \\
\hline Denitrification rate $[\mathrm{mg}$ nitrite & $1 \cdot 14$ & $0 \cdot 95$ & $0 \cdot 39$ & $0 \cdot 54$ & $0 \cdot 18$ & - \\
\hline$\left.(\mathrm{g} \text { bacteria })^{-1} \mathrm{~min}^{-1}\right]$ & $s=0 \cdot 15$ & $s=0.39$ & $s=0 \cdot 17$ & $s=0.12$ & $s=0.065$ & ND \\
\hline Optimum pH & $7 \cdot 5^{*}$ & ND & ND & ND & ND & ND \\
\hline Optimum temperature & $30^{\circ} \mathrm{C}$ & $30^{\circ} \mathrm{C}$ & $30^{\circ} \mathrm{C}$ & $30^{\circ} \mathrm{C}$ & $30^{\circ} \mathrm{C}$ & ND \\
\hline $\mathrm{G}+\mathrm{C}(\mathrm{mol} \%)$ & $60 \cdot 4$ & $60 \cdot 8$ & $60 \cdot 3$ & $60 \cdot 5$ & $60 \cdot 5$ & $65 \cdot 2$ \\
\hline \multicolumn{7}{|c|}{ Reaction to antimicrobial agents (amount per disk): } \\
\hline Rifampicin $(5 \mu \mathrm{g})$ & $\mathrm{R}$ & $\mathrm{R}$ & $\mathrm{S}$ & S & $\mathrm{R}$ & $\mathrm{S}$ \\
\hline Sulfisoxazole $(250 \mu \mathrm{g})$ & $\mathrm{R}$ & S & S & $\mathrm{R}$ & $\mathrm{S}$ & $\mathrm{R}$ \\
\hline Tetracycline $(30 \mu \mathrm{g})$ & $\mathrm{S}$ & S & $\mathrm{S}$ & $\mathrm{S}$ & S & $\mathrm{R}$ \\
\hline Ampicillin $(10 \mu \mathrm{g})$ & $\mathrm{S}$ & S & $\mathrm{S}$ & S & S & $\mathrm{R}$ \\
\hline Penicillin $\mathrm{G}(10 \mu \mathrm{g})$ & $\mathrm{R}$ & $\mathrm{S}$ & $\mathrm{S}$ & $\mathrm{S}$ & $\mathrm{S}$ & $\mathrm{S}$ \\
\hline \multicolumn{7}{|l|}{ Carbohydrate metabolism: } \\
\hline Salicin & $(+)$ & + & - & + & $(+)$ & + \\
\hline Citrate & + & + & $(+)$ & + & - & + \\
\hline Fumarate & + & + & + & + & + & + \\
\hline L-Malinate & + & + & + & + & + & + \\
\hline Malonate & + & + & $(+)$ & + & $(+)$ & + \\
\hline Pyruvate & + & + & $(+)$ & + & + & + \\
\hline L-Tartarate & + & + & $(+)$ & + & $(+)$ & + \\
\hline Urea & - & $(+)$ & - & $(+)$ & - & + \\
\hline L-Ornithine & - & - & - & - & - & $(+)$ \\
\hline$m$-Hydroxybenzoate & + & + & - & $(+)$ & - & + \\
\hline trans-Aconitate & $(+)$ & - & - & - & - & + \\
\hline D-Glucuronate & + & + & - & + & $(+)$ & + \\
\hline Glycolate & + & + & - & + & + & + \\
\hline D- $\beta$-Hydroxybutyrate & + & + & - & + & + & + \\
\hline$\alpha$-Ketovalerate & + & + & - & + & + & + \\
\hline L-Lactate & + & + & - & + & + & + \\
\hline Maleinate & $(+)$ & - & - & - & - & + \\
\hline D-Saccharate & + & $(+)$ & - & + & $(+)$ & + \\
\hline Succinate & + & $(+)$ & - & + & + & + \\
\hline D-Tartarate & + & - & - & + & $(+)$ & + \\
\hline Gentisate & $(+)$ & $(+)$ & - & $(+)$ & - & + \\
\hline$p$-Coumarate & $(+)$ & - & - & - & - & + \\
\hline Hippurate & + & $(+)$ & - & $(+)$ & - & + \\
\hline DL-2- $\gamma$-Aminobutyrate & + & $(+)$ & - & + & - & + \\
\hline L-Alanine & + & $(+)$ & - & + & $(+)$ & + \\
\hline L-Arginine & + & $(+)$ & - & $(+)$ & $(+)$ & + \\
\hline L-Glutamate & + & + & - & + & + & + \\
\hline L-Lysine & + & + & - & + & + & + \\
\hline L-Serine & + & - & - & $(+)$ & - & + \\
\hline L-Histidine & - & - & - & - & - & $(+)$ \\
\hline Aesculin & $(+)$ & - & - & $(+)$ & - & + \\
\hline
\end{tabular}

* Data from Gumaelius et al. (1996).

activated sludge which could be used in biosensors analysing inhibition of denitrification (Gumaelius et al., 1996) or denitrification status. About 1500 bacterial strains were isolated from five different wastewater treatment plants of which only efficient denitrifying strains were selected for partial 16S rDNA analysis. Five of these strains, $110,5.38 \mathrm{~g}, 123^{\mathrm{T}}$, P17 and $2.99 \mathrm{~g}$, possessed high sequence similarity. These strains included the most efficient denitrifiers of the selection and had no lag phase when switching from oxygen respiration to nitrite respiration. Considering this, these five strains were regarded as relevant potential biomarkers and for this purpose the five strains were further characterized. 


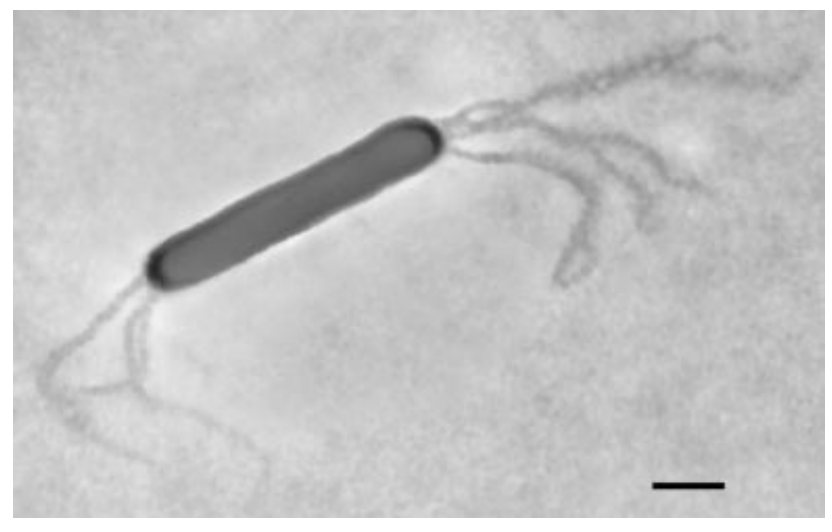

Fig. 1. A strain 110 bacterium picked from an overnight culture on nutrient agar. Flagella have been stained according to Gray (Gerhardt et al., 1981). Bar, $1 \mu \mathrm{m}$.

\section{METHODS}

Source of strains. The strains were all isolated from activated sludge in municipal wastewater treatment plants. Strains 110 and $123^{\mathrm{T}}$ were isolated from Gustavsberg (Stockholm, Sweden), P17 from Pisec (Slovakia), and 2.99g and 5.38g from Käppala treatment plant (Stockholm, Sweden). The wastewater treatment plants reported biological nitrogen removal. Comamonas terrigena (IAM 12052) was used as reference throughout the study.

Morphological analysis. Morphological features were studied using a phase-contrast microscope (Olympus BH-2). Photographs were made using an Olympus SC36 type 12 camera connected to the microscope. PJ800 or PJC1600 photographic films (Kodak) were used. Gram staining and flagella staining were performed using Gray's method. Staining of polysaccharides was done using Alcalian blue and staining of inclusion bodies (polyhydroxyalkanoate; PHA) with Sudan black (Gerhardt et al., 1981).

Physiological tests. Oxidase and catalase activities were analysed according to Gerhardt et al. (1981) and antibiotic sensitivity tests were performed using PDM Antibiotic Sensitivity Discs 2 (AB Biodisk) on nutrient agar plates (Difco). Saline tolerance was investigated using nutrient broth medium and nutrient agar (Difco) with the addition of $\mathrm{NaCl}$.

Amplification of the nitrite reductase gene. For determination of nitrite reductase type a PCR-based method developed by Braker et al. (1998) was used. Primers used were either nirS1F and nirS6R for detection of the $\mathrm{cd}_{1}$-type nitrite reductase or nirK $1 F$ and nirK5R for the Cu-type nitrite reductase. PCR reactions were run with 5 pmol of each primer. The program used was a three temperature cycling program that ran for 30 cycles starting with denaturation at $96^{\circ} \mathrm{C}$ for $30 \mathrm{~s}$ followed by annealing at $41^{\circ} \mathrm{C}$ for $40 \mathrm{~s}$ and extension at $72^{\circ} \mathrm{C}$ for $40 \mathrm{~s}$. Finally, a $10 \mathrm{~min}$ incubation was performed at $72{ }^{\circ} \mathrm{C}$. Pseudomonas stutzeri (ATCC 14405) was used as positive control and Alcaligenes faecalis (ATCC 8750 ${ }^{\mathrm{T}}$ ) was used as negative control.

Determination of the denitrification rate. The denitrification rate was measured as nitrite consumed over time. The method of Gumaelius et al. (1996) was used with some small modifications. Bacteria were added on a wet mass basis, $3.3 \mathrm{~g}$ bacteria per litre nutrient broth medium. Experiments were performed in microtitre plates where each well contained $250 \mu \mathrm{l}$ bacterial suspension. Nitrite was added as $\mathrm{NaNO}_{2}$ at a concentration of $50 \mathrm{mg}$ nitrite per litre. The rate experiments were repeated 6-14 times for each species.

Biochemical characterization. Biochemical characteristics were analysed by using the API 20NE kit (BioMérieux) and the Phene Plate system (PhP; BioSys Inova). PhP is a miniaturized metabolic fingerprinting system designed to reveal bacterial strains at subspecies level.

Bacterial metabolism of various substrates was quantitatively measured via a $\mathrm{pH}$ indicator, thus creating a biochemical fingerprint (Möllby et al., 1993; Kühn et al., 1991; Katouli et al., 1997). The studied strains, 110, 123 $2.99 \mathrm{~g}, 5.38 \mathrm{~g}$ and P17, and Comamonas terrigena IAM 12052 were inoculated in duplicate into $\mathrm{PhP}$ microtitre plates, according to the manufacturer's instructions. Both PhP-48 and PhP-EX plates were used. Consequently, metabolic activity with 102 different carbon sources was investigated (see Table 1). Incubations were performed at $30{ }^{\circ} \mathrm{C}$ for $100 \mathrm{~h}$ and absorbance was measured with an Easy Reader EAR 340AT (SLT-Labinstruments). The spectrophotometer was engineered using the PhP system software, version 1.12 (BioSys Inova). Only statistically significant reactions, at the $99.7 \%$ level, were interpreted as positive. The significance level was calculated as 3 standard deviations from a mean value based on samples taken at time zero and reference samples. Results close to this level, between 2 and 3 standard deviations, were reported as $(+)$.

Determination of the $\mathbf{G}+\mathbf{C}$ content. Genomic DNA was prepared according to the procedure of Wilson (1987). The HPLC technique (Mesbah et al., 1989) was used for the determination of the $\mathrm{G}+\mathrm{C}$ content of strains $110,123^{\mathrm{T}}$, $2.99 \mathrm{~g}, 5.38 \mathrm{~g}, \mathrm{P} 17$ and the control strain, Comamonas terrigena.

In vitro amplification of the 16S rRNA gene. The 16S rRNA genes were amplified directly from the bacterial genome in a semi-nested fashion (Pettersson, 1997). The first amplification of the $16 \mathrm{~S}$ rRNA gene was performed with primers complementary to the regions close to the $5^{\prime}$ and $3^{\prime}$ termini of the gene. Freshly cultivated bacterial cells were added to the PCR mix. Amplification was performed using primers 605 and 621 (Pettersson, 1997). The PCR products were used as template in two subsequent and different reactions. The latter amplifications were performed using primer pairs $605 / 614 \mathrm{~B}$ and 603/621B (Pettersson, 1997). This resulted in two different biotinylated PCR products, suitable for solidphase DNA sequencing. The primer pair 605 and 614B generated a fragment with an approximate length of $900 \mathrm{bp}$ and primers 603 and $621 \mathrm{~B}$ gave a PCR product of about $1200 \mathrm{bp}$. These two products overlap by almost $600 \mathrm{nt}$. The PCRs were performed with 5 pmol of each primer for 30 cycles. The profile for each cycle was denaturation at $96^{\circ} \mathrm{C}$ for $15 \mathrm{~s}$, annealing at $65^{\circ} \mathrm{C}$ for $30 \mathrm{~s}$ and extension at $72{ }^{\circ} \mathrm{C}$ for $60 \mathrm{~s}$. Finally, a $10 \mathrm{~min}$ incubation was performed at $72{ }^{\circ} \mathrm{C}$.

Automated solid-phase 16S rDNA sequencing. Automated solid-phase DNA sequencing with an Automated Laser Fluorescence System (Pharmacia Biotech) was performed on each strand after separation with streptavidin-coated super paramagnetic beads (Dynabeads M-280 Streptavidin; Dynal). The sequences were determined in both directions by analysis of both the immobilized and eluted strands (Hultman et al., 1991). Sequencing primers used were USP, 622F, 596F, 585F, 538F and 597F (Pettersson, 1997). 


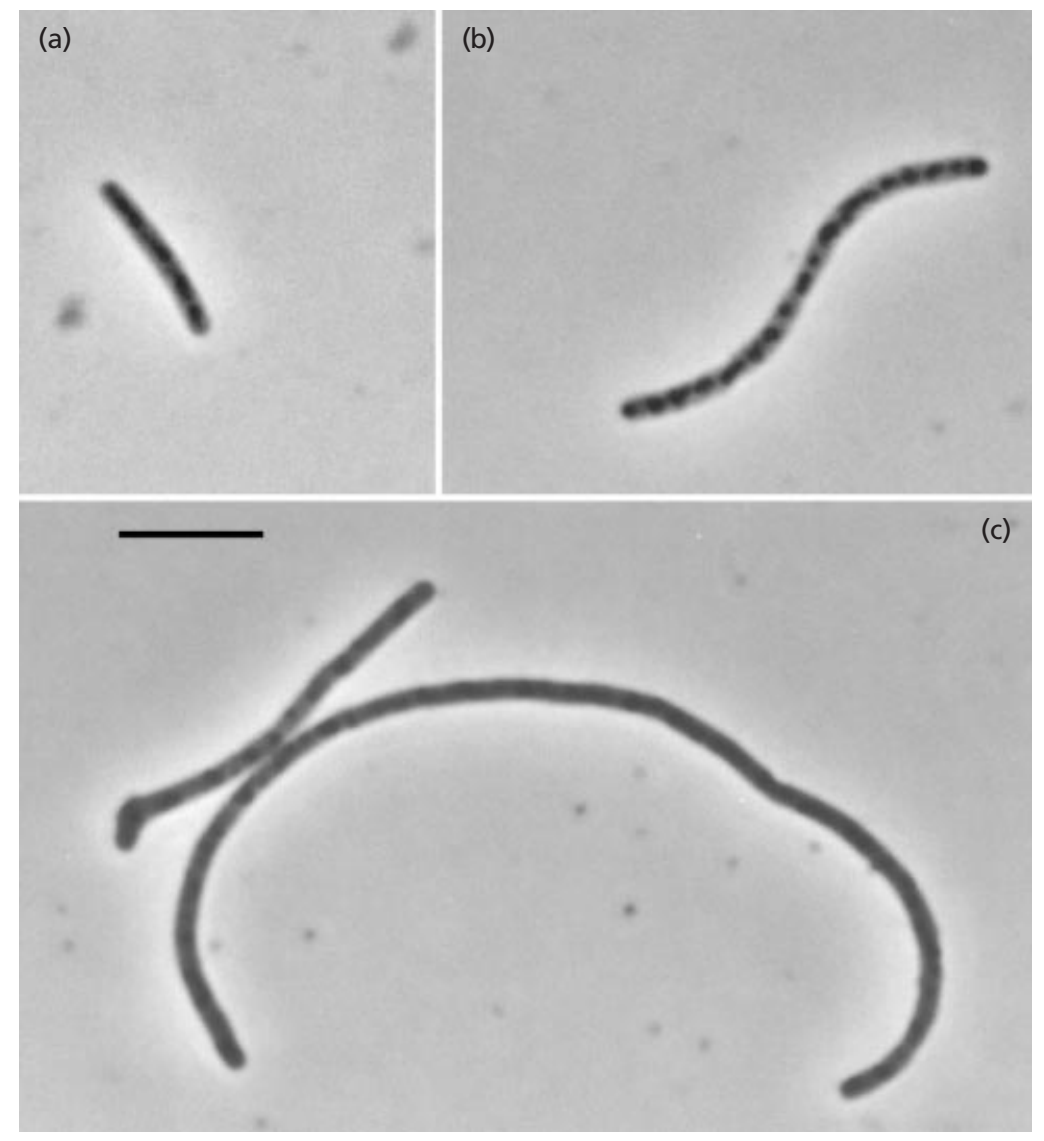

Fig. 2. Growth of strain $123^{\top}$ in nutrient broth under aerobic conditions. Samples were taken at 1 (a), 2 (b) or $4 \mathrm{~h}$ (c) after inoculation. Bar, $5 \mu \mathrm{m}$.

Phylogenetic analysis. The sequences generated in this work were all searched against GenBank using the advanced gapped BLAST option (Altschul et al., 1997) at the NCBI home page (http://www.ncbi.edu). Selected sequences were retrieved and aligned manually to a set of operational taxonomic units (OTUs), which were downloaded from the Ribosomal Database Project (Maidak et al., 1999; Ribosomal Database Project RDP-II, 1999). The alignment was performed using the Genetic Data Environment (GDE) (Smith, 1992). A secondary structure of the 16S rRNA molecule of Escherichia coli was used to facilitate identification of stems and loops in the alignment procedure. Phylogenetic trees were inferred using programs contained in the phylogenetic inference package, PHYLIP version 3.573, (Felsenstein, 1993). Evolutionary distance trees were constructed from distances corrected by the two-parameter model of Kimura (1980) with a transition/transversion ratio set to 2.0 using the neighbour-joining algorithm (Saitou \& Nei, 1987). Statistical tests were performed using the bootstrap option (Felsenstein, 1985). The construction of the maximum-likelihood tree was performed with the DNAML program using the F84 model of molecular evolution with a transition/transversion ratio of 2.0 and applying global rearrangement for finding the optimal tree.

Nucleotide accession numbers. The GenBank accession numbers for the $16 \mathrm{~S}$ rRNA sequences of the reference strains used for comparison in this study are as follows: Acidovorax avenae subsp. avenae ATCC 19307 ${ }^{\mathrm{T}}$, AB021421; Acidovorax konjaci ATCC 33996 ${ }^{\mathrm{T}}$, AF078760; Acidovorax sp. strain IMI 357678, AF078763; Alcaligenes faecalis ATCC 8750 ${ }^{\mathrm{T}}$, M22508; Aquaspirillum metamorphum ATCC 15280 ${ }^{\mathrm{T}}$, AF078757; Aquaspirillum psychrophilum ATCC $33335^{\mathrm{T}}$,
AF078755; Bordetella bronchiseptica S-1, X57026; Brachymonas denitrificans JCM 9216 ${ }^{\mathrm{T}}$, D14320; Comamonas sp. strain 12022, AF078773; Comamonas terrigena ATCC $8461^{\mathrm{T}}$, AF078772; Comamonas terrigena IAM 12052, AB021418; Comamonas testosteroni NCTC 10698 ${ }^{\mathrm{T}}$, M11224; Delftia acidovorans ATCC 15668 ${ }^{\mathrm{T}}$, AF078774; Hydrogenophaga taeniospiralis ATCC 49743 ${ }^{\mathrm{T}}$, AF078768; Hydrogenophaga palleronii ATCC 17724 ${ }^{\mathrm{T}}$, AF078769; Ideonella dechloratans CCUG 30898 ${ }^{\mathrm{T}}$, X72724; Lautropia mirabilis NCTC $12852^{\mathrm{T}}$, X73223; Leptothrix discophora ATCC 51168, L33974; Polaromonas vacuolata ATCC 51984 ${ }^{\mathrm{T}}$, U14585; Rhodoferax fermentans JCM 7818 ${ }^{\mathrm{T}}$, D16211; Roseateles depolymerans DSM 11813 ${ }^{\mathrm{T}}$, AB003623; Rubrivivax gelatinosus ATCC 17011 ${ }^{\mathrm{T}}$, D16213; Sphaerotilus natans strain 565, Z18534; Sutterella wadsworthensis ATCC 51579 ${ }^{\mathrm{T}}$, L37786; Variovorax paradoxus MBIC 3839, AB008000; Xylophilus ampelinus ATCC 33914 ${ }^{\mathrm{T}}$, AF078758; isolate rA3, AB021355; isolate rA6, AB021357.

\section{RESULTS AND DISCUSSION}

\section{Morphology and growth rate}

All strains appeared as Gram-negative rods when grown on nutrient agar plates. Several flagella were present attached at the polar ends (Fig. 1) and all strains were motile. These features are in good agreement with an earlier morphological description of the Comamonas genus (Wen et al., 1999). A thick layer of polysaccharide is produced around the cell chains. Inclusion bodies are also produced in liquid culture. 
Table 2. Differentiation of the three Comamonas species

+ , Present in all strains; $(+)$, present in $90-99 \%$ of the strains; D, present in $11-89 \%$ of the strains; $(-)$, absent in $90-99 \%$ of the strains; - , absent in all strains; $\mathrm{S}$, sensitive; $\mathrm{R}$, resistant.

\begin{tabular}{|c|c|c|c|}
\hline Characteristic & $\begin{array}{l}\text { Comamonas } \\
\text { denitrificans* }\end{array}$ & $\begin{array}{c}\text { Comamonas } \\
\text { testosteroni } \dagger\end{array}$ & $\begin{array}{c}\text { Comamonas } \\
\text { terrigena } \dagger\end{array}$ \\
\hline Production of inclusion bodies containing PHA & + & ND & ND \\
\hline \multicolumn{4}{|l|}{ Growth on: } \\
\hline Glycerol & - & D & $(-)$ \\
\hline 5-Keto-D-gluconate & - & $(-)$ & - \\
\hline Citrate & + & + & $(-)$ \\
\hline Pyruvate & + & $\mathrm{D}$ & $\mathrm{D}$ \\
\hline$m$-Hydroxybenzoate & $\mathrm{D}$ & + & $\mathrm{D}$ \\
\hline Aconitate & $\mathrm{D}$ & $\mathrm{D}$ & $\mathrm{D}$ \\
\hline Glycolate & + & + & $(-)$ \\
\hline L-Alanine & + & $\mathrm{D}$ & $\mathrm{D}$ \\
\hline L-Arginine & + & - & $(-)$ \\
\hline L-Serine & $\mathrm{D}$ & $(-)$ & - \\
\hline L-Histidine & - & + & $(-)$ \\
\hline D-Gluconate & - & + & $\mathrm{D}$ \\
\hline Caprate & - & $\mathrm{D}$ & $\mathrm{D}$ \\
\hline Sensitivity to penicillin & $\mathrm{S}$ & $\mathrm{R}$ & $\mathrm{D}$ \\
\hline Nitrate reduction & + & $\mathrm{D}$ & $(+)$ \\
\hline Nitrite reduction & + & - & $(-)$ \\
\hline $\mathrm{G}+\mathrm{C}$ content $(\mathrm{mol} \%)$ & $60 \cdot 3-60 \cdot 8$ & $62 \cdot 5-64 \cdot 5$ & $59 \cdot 7-66 \cdot 7$ \\
\hline
\end{tabular}

* As determined in this study for the strains 110 (ATCC 700937) 123 ${ }^{\mathrm{T}}$ (ATCC 700936 ${ }^{\mathrm{T}}$ ), 2.99g (ATCC 700940) and P17 (ATCC 700939).

$\dagger$ Data from Willems et al. (1991).

The results obtained after staining with Sudan black suggested the content to be PHA. This sort of inclusion body has been reported for Comamonas acidovorans (Sudesh et al., 1998), later renamed as Delftia acidovorans (Wen et al., 1999). When cultivated aerobically in liquid nutrient broth medium, long chains of filamentous clusters were formed for all strains (Fig. 2).

When grown on nutrient agar, all strains formed yellow-white colonies, although strain P17 produced a pigment that made the agar brownish and bacterium $5.38 \mathrm{~g}$ formed dryer colonies that adhered more to the agar than the other strains.

\section{Physiological analysis}

The strains were oxidase and catalase-positive. Bacterial growth was detected at 20,30 and $37^{\circ} \mathrm{C}$ but not at $4{ }^{\circ} \mathrm{C}$. Growth was also detected on nutrient agar with $2 \% \mathrm{NaCl}$. All strains survived in $5 \% \mathrm{NaCl}$, but not in $9 \% \mathrm{NaCl}$. Eight different antimicrobial agents were tested (Table 1). Strain 110 was resistant to three of the eight agents, whereas the others were resistant to only one or none. Three out of five strains showed no sensitivity towards rifampicin.

\section{Characteristics of denitrification}

Nitrite reductase is the first enzyme in the denitrification process, reducing nitrite to NO. Two types of nitrite reductase have been found so far. One containing a copper centre (NirK) and one containing haems $c$ and $d_{1}$ (NirS). It is not yet established how these enzymes are distributed among taxonomic families; however, they are both regarded to be widespread (Zumft, 1997). The two types seems to be mutually exclusive in a given species, but both types have been found at the genus level (Coyne et al., 1989). Among the denitrifiers studied all five strains contained the $\mathrm{cd}_{1}$-type of nitrite reductase, even though the strains were isolated at different locations.

Denitrification rates are reported in Table 1. Strains 110 and $123^{\mathrm{T}}$ showed higher denitrification rates than the others.

\section{Biochemical characterization}

The strains studied were tested for a total of 102 carbon sources in the API $20 \mathrm{NE}$ kit and in the $\mathrm{PhP}$ system. Results are presented in Table 1. Only 29 of the compounds gave a positive reaction for any of the strains tested. Out of these 29, 5 were exclusively positive for Comamonas terrigena. This bacterium was 


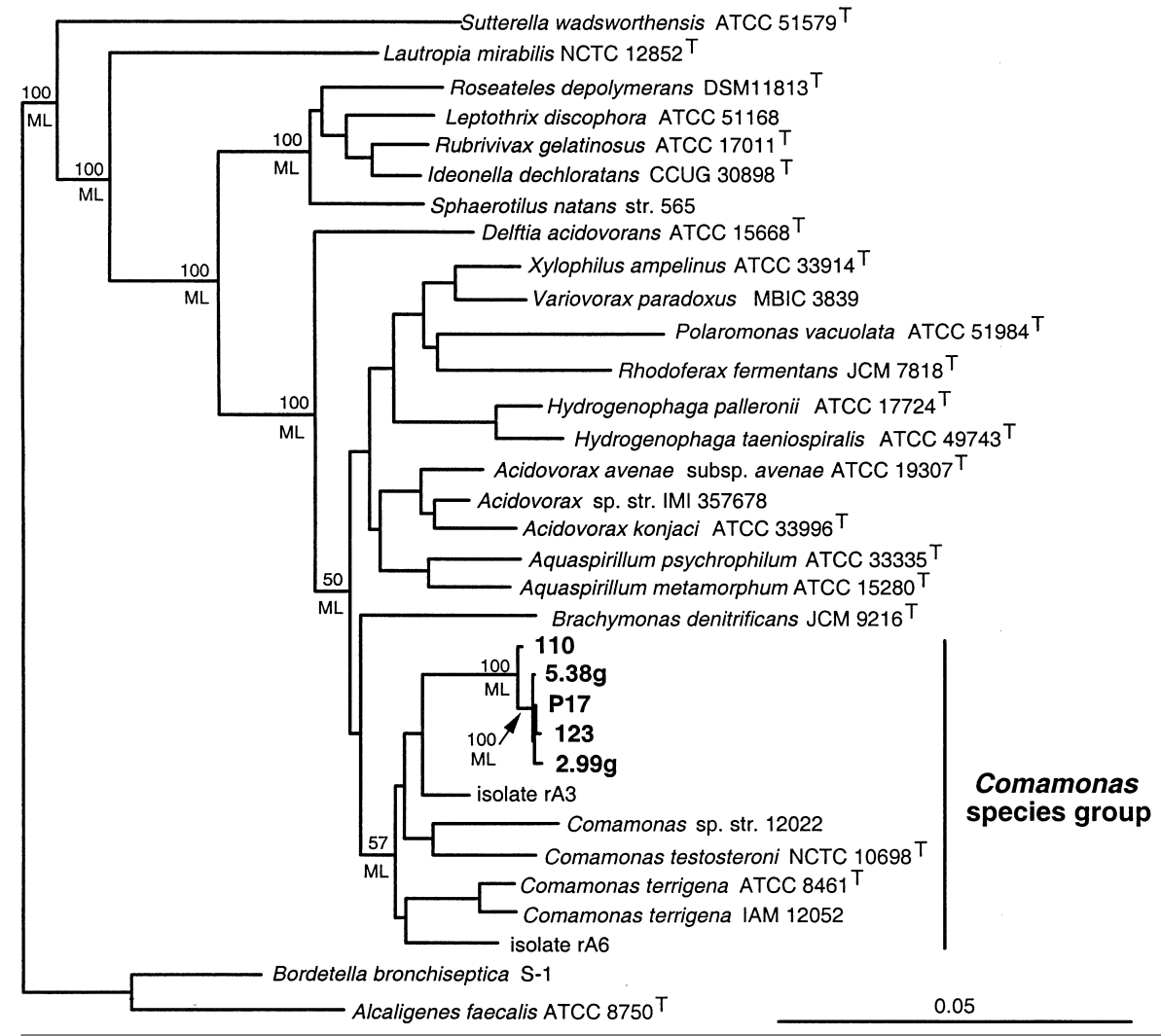

Fig. 3. A phylogenetic tree derived by neighbour-joining (Saitou \& Nei, 1987) showing the position of strains $110,123^{\top}$, $2.99 \mathrm{~g}, 5.38 \mathrm{~g}$ and $\mathrm{P} 17$ within the Comamonas species group. A member of the $\beta$-subclass of the Proteobacteria, Alcaligenes faecalis ATCC $8750^{\top}$, served as outgroup. Statistical support for the topology was obtained from bootstrap analysis performed by 500 resamplings of the data set and by using maximum-likelihood (indicated by percentage values and $\mathrm{ML}$, respectively, at the nodes regarded as relevant for this study). The Comamonas species group is indicated by a vertical bar. The scale bar denotes the number of substitutions per nucleotide position.

shown to be the most metabolically active of the strains. Strains $110,2.99 \mathrm{~g}$ and $123^{\mathrm{T}}$ showed similar patterns with 15-22 carbon sources. Strain P17 showed significant activity with only 10 carbon sources, while strain $5.38 \mathrm{~g}$ showed significant metabolic activity with only two tested carbon sources.

\section{Determination of $\mathbf{G}+\mathbf{C}$ content}

The strains tested were shown to be very similar in their $\mathrm{G}+\mathrm{C}$ content, between $60 \cdot 3$ and $60.8 \mathrm{~mol} \%$, compared to Comamonas terrigena with a value of $65 \cdot 2 \mathrm{~mol} \%$. The values of the individual strains, a mean of three independent analyses of the same DNA sample, are presented in Table 1 . These similarities further strengthen the idea that the strains belong to the same species. A compilation of physiological features for the three species of the genus Comamonas is shown in Table 2. Results not evaluated in this study have been collected from Willems et al., (1991).

\section{Phylogenetic analysis}

Nucleotide sequences of the 16S rRNA gene were determined for strains $110,123^{\mathrm{T}}, 2.99 \mathrm{~g}, 5.38 \mathrm{~g}$ and P17. The obtained primary structures were 1443,1442 , 1446, 1444 and 1441 bp in length, respectively. Unambiguous sequences were obtained by applying the direct solid-phase 16S rDNA sequencing technique using both strands (Hultman et al., 1991). The sequences differed slightly from each other with $16 \mathrm{~S}$
rDNA sequence similarity values ranging between $99 \cdot 7$ and $99.9 \%$ (not shown), with strain 110 being the most divergent. The resulting sequences were checked for their uniqueness against deposited data in GenBank and the 100 best hits, including those for noncultivated and non-taxonomically characterized organisms, were retrieved and merged into the alignment.

Different data sets were generated, correcting for gaps and ambiguously aligned positions; sets without any position removed were used to establish evolutionary relationships. Moreover, changes in the number of OTUs and outgroups were determined. A representative tree inferred by neighbour-joining is presented in Fig. 3 and its overall topology resembles that published previously by Wen et al. (1999). Alcaligenes faecalis served as outgroup. The tree was inferred from a data set only consisting of nucleotide positions having a conserved composition in more than $50 \%$ of the used sequences. Statistical testing of the stability of the nodes was performed by bootstrap analysis by resampling the data set 500 times. Also, the maximumlikelihood method resulted in a topology essentially congruent with that produced by neighbour-joining (Fig. 3). The obtained bootstrap value of $57 \%$ showed that the phylogenetic grouping of Comamonas species shown in Fig. 3 has relatively low statistical support. Despite the relatively low bootstrap value for the Comamonas species group, a maximum-likelihood tree supported this phylogenetic entity (not shown). Shifts of the internal branching order within some of the clades could be observed, but this was not further 
studied in this work. Strains $110,123^{\mathrm{T}}, 2.99 \mathrm{~g}, 5.38 \mathrm{~g}$ and P17 grouped tightly together and with species of the genus Comamonas. The Comamonas species group has been indicated in Fig. 3. Strain 110 formed an early branch of the subclade containing denitrifying strains in all trees (Fig. 3). Interestingly, the closest neighbour was found to be a non-characterized isolate from the aeration tank of an activated sludge process in Japan (Watanabe et al., 1999), sharing 16S rDNA sequence similarity of $96 \cdot 6-96.7 \%$ (not shown). Furthermore, the five strains in this study were shown to be $94 \cdot 5-95 \cdot 6 \%$ (not shown) similar to other members of the Comamonas species group, thus falling below the upper and general limit of $97 \%$ used as a cut-off value for species delineation (Stackebrandt \& Goebel, 1994).

As noted above, the Comamonas species group was supported by only moderate bootstrap values. However, by removing Brachymonas denitrificans from the data set, the tree in Fig. 3 gained a marked increase in the node stability of the Comamonas branch, raising the bootstrap support value from $57 \%$ to $68 \%$ (not shown). This reflects that the $16 \mathrm{~S}$ rDNA sequences of the members of the family Comamonadaceae have a somewhat low resolving power. Nevertheless, we believe that strains $110,123^{\mathrm{T}}, 2.99 \mathrm{~g}, 5.38 \mathrm{~g}$ and $\mathrm{P} 17$ have been placed in the Comamonas species group with a high cladistic confidence. Besides sharing an ancestral branch in all computed trees, the members of this group showed a unique base pair composition, $\mathrm{G} \cdot \mathrm{C}_{(603 \cdot 635)}$, in the resulting $16 \mathrm{~S}$ rRNA molecule (Escherichia coli numbering; Brosius et al., 1978). This feature is generally not seen among taxa of the $\beta$ - and $\gamma$-Proteobacteria, thus being idiosyncratic for the Comamonas species group.

Nucleotide motifs of the 16S rRNA gene were also found for strains $110,123^{\mathrm{T}}, 2.99 \mathrm{~g}, 5.38 \mathrm{~g}$ and $\mathrm{P} 17$. Totalling four, the positions of these attributes could be regarded as two adjacently positioned canonical base pairs in the matured 16S rRNA molecule. The composition of the actual pairs are $\mathrm{U} \cdot \mathrm{A}_{(953 \cdot 1228)}$ and $\mathrm{C} \cdot \mathrm{G}_{(954 \cdot 1226)}$ (position 1227 is a non-paired unilaterally bulged residue). These nucleotide compositions are commonly found in the domain Bacteria, but not in the family Comamonadaceae and have not been found in the domain Archaea. The pair U· $\mathrm{A}_{(953 \cdot 1228)}$ was shared with Streptosporangium and relatives, class Mollicutes (except for the hominis and the spiroplasma phylogenetic groups), Aeromicrobium erythreum subgroup (three species) and Brachybacterium faecium subgroup (four species). Only species belonging to the genus Rubrobacter (two species) showed identical composition in both these pairs. As well as the species of these phylogenetic entities, exceptions were only found in a few other $16 \mathrm{~S}$ rDNA sequences. Consequently, it is likely that the denitrifying strains 110 , $123^{\mathrm{T}}, 2.99 \mathrm{~g}, 5.38 \mathrm{~g}$ and $\mathrm{P} 17$ are detected to the exclusion of most other prokaryotes by the construction of probes harbouring the sequence motifs 5'-GATGATGTTCTTTAATTC-3' and/or 5'-GGCTAGAAACGTC-3'.

\section{Taxonomic considerations}

As judged from the morphology, physiology, phenotypic tests and genetic analysis based 16S rDNA and the $\mathrm{G}+\mathrm{C}$ content, strains $110,5.38 \mathrm{~g}, 123^{\mathrm{T}}, \mathrm{P} 17$ and $2.99 \mathrm{~g}$ can be regarded as constituting a somewhat heterogenic subclade within the Comamonas species group. The most divergent strains were 110 and $5.38 \mathrm{~g}$. Strain 110 formed an early branch of the actual subclade in all derived trees and it also showed a slightly altered physiological response to the eight antimicrobial agents used for testing. Strain $5.38 \mathrm{~g}$ differed from the others by forming dryer colonies and showed a marked difference in biochemical features as judged by phenotypic testing. Despite being closely related with regard to $16 \mathrm{~S}$ rRNA gene similarity (Fig. 3 ) we stress that the taxonomy of strain $5.38 \mathrm{~g}$ should await further genetic data such as DNA-DNA reassociation, PFGE, amplified fragment length polymorphism (AFLP) and enterobacterial repetitive intergenic consensus (ERIC)-, BoxA subunit (BOX)-, repetitive extragenic palindromic (REP)- and/or randomly amplified polymorphic DNA (RAPD)PCR. Preferably, these studies should be performed including more isolates of this group to discern the range of heterogeneity among the members of these denitrifying strains. Therefore, we propose that strains $110,123^{\mathrm{T}}, \mathrm{P} 17$ and $2.99 \mathrm{~g}$ should be classified in a new species for which we propose the name Comamonas denitrificans sp. nov. The type strain of Comamonas denitrificans is $123^{\mathrm{T}}\left(=\right.$ ATCC $\left.700936^{\mathrm{T}}\right)$.

\section{Description of Comamonas denitrificans sp. nov.}

Comamonas denitrificans (de.ni.tri'fi.cans. L. prep. de away from; L. n. nitrum soda; N.L. n. nitrum nitrate; M.L. v. denitrifico to denitrify; N.L. part. adj. denitrificans denitrifying).

Straight or slightly curved rods, $2-6 \mu \mathrm{m}$ long and 1-2 $\mu \mathrm{m}$ wide. When grown on nutrient agar plates appear as single cells or as filaments, motile by means of polar flagella, form yellow-white colonies and strain P17 produces a brownish pigment. Gram-negative, oxidase- and catalase-positive. Grow at 20, 30 and $37^{\circ} \mathrm{C}$ but not at $4{ }^{\circ} \mathrm{C}$. Reduce nitrate to nitrogen gas (the only species in the genus Comamonas to do so) and contain $\mathrm{cd}_{1}$-type nitrite reductase. All strains utilize fumarate, L-malonate, pyruvate, glycolate, D- $\beta$-hydroxybutyrate, $\alpha$-ketovalerate, L-lactate, L-glutamate and L-lysine. Grow in $2 \%$ saline solution and survive in $5 \% \mathrm{NaCl}$, but not in $9 \% \mathrm{NaCl}$. Three of the four strains are rifampicin-tolerant. Found in activated sludge with biological nitrogen removal properties. The DNA $\mathrm{G}+\mathrm{C}$ content varies between 60.4 and $60 \cdot 8 \mathrm{~mol} \%$. Type strain is $123^{\mathrm{T}}\left(=\right.$ ATCC $\left.700936^{\mathrm{T}}\right)$.

\section{ACKNOWLEDGEMENTS}

We want to thank Kaj Kauko for his work with photographs and bacterial staining. We would also like to thank Helena Edin for her initial work isolating these strains from their 
natural environment. Bertil Pettersson is indebted to the Foundation for Strategic Research.

\section{REFERENCES}

Altschul, S. F., Madden, T. L., Schaffer, A. A., Zhang, J., Zhang, Z., Miller, W. \& Lipman, D. J. (1997). Gapped BLAST and PSI-BLAST: a new generation of protein database search programs. Nucleic Acids Res 25, 3389-3402.

Braker, G., Fesefeldt, A. \& Witzel, K.-P. (1998). Development of primer systems for amplification of nitrite reductase genes (nir $K$ and nirS) to detect denitrifying bacteria in environmental samples. Appl Environ Microbiol 64, 3769-3775.

Brosius, J., Palmer, M. L., Kennedy, P. J. \& Noller, H. F. (1978). Complete nucleotide sequence of a $16 \mathrm{~S}$ ribosomal RNA gene from Escherichia coli. Proc Natl Acad Sci US A 75, 4801-4805.

Coyne, M. S., Arunakumari, A., Averill, B. A. \& Tiedje, J. M. (1989). Immunological identification and distribution of dissimilatory heme cdl and nonheme copper nitrite reductases in denitrifying bacteria. Appl Environ Microbiol 55, 2924-2931.

Felsenstein, J. (1985). Confidence limits on phylogenies: an approach using the bootstrap. Evolution 39, 783-791.

Felsenstein, J. (1993). PHYLIP (Phylogeny Inference Package) version 3.57. Seattle: Department of Genetics, University of Washington.

Gerhardt, P., Murray, R., Costilow, R., Nester, E., Wood, W., Krieg, N. \& Phillips, G. (1981). Manual of Methods for General Microbiology. Washington, DC: American Society for Microbiology.

Gumaelius, L., Smith, E. H. \& Dalhammar, G. (1996). Potential biomarker for denitrification of wastewaters: Effects of process variables and toxicity. Water Res 30, 3025-3031.

Hallin, S., Rothman, M. \& Pell, M. (1996). Adaption of denitrifying bacteria to acetate and methanol in activated sludge. Water Res 30, 1445-1450.

Hultman, T., Bergh, S., Moks, T. \& Uhlén, M. (1991). Bidirectional solid phase sequencing of in vitro-amplified plasmid DNA. BioTechniques 10, 84-93.

Katouli, M., Foo, E., Kühn, I. \& Möllby, R. (1997). Evaluation of Phene Plate generalized microplate for metabolic fingerprinting and for measuring fermentative capacity of mixed bacterial populations. J Appl Microbiol 82, 511-518.

Kimura, M. (1980). A simple method for estimating evolutionary rates of base substitutions through comparative studies of nucleotide sequences. J Mol Evol 16, 111-120.

Kühn, I., Allestam, G., Stenström, T. A. \& Möllby, R. (1991). Biochemical fingerprinting of water coliform bacteria, a new method for measuring phenotypic diversity and for comparing different bacterial populations. Appl Environ Microbiol 57, 3171-3177.

Lemmer, H., Roth, D. \& Schade, M. (1994). Population densities and enzyme activities of heterotrophic bacteria in sewer biofilms and activated sludge. Water Res 28, 1341-1346.

Magnusson, G., Edin, H. \& Dalhammar, G. (1998). Characterisation of efficient denitrifying bacteria strains isolated from activated sludge by $16 \mathrm{~S}-\mathrm{rDNA}$ analysis. Water Sci Technol 38, $8-9$.
Maidak, B. L., Cole, J. R., Parker, Jr, C. T. \& 11 other authors (1999). A new version of the RDP (Ribosomal Database Project). Nucleic Acids Res 27, 171-173.

Mesbah, M., Premachandran, U. \& Whitman, W. B. (1989). Precise measurement of the $\mathrm{G}+\mathrm{C}$ content of deoxyribonucleic acid by high-performance liquid chromatography. Int $J$ Syst Bacteriol 39, 159-167.

Möllby, R., Kühn, I. \& Katouli, M. (1993). Computerized biochemical fingerprinting-A new tool for typing of bacteria. Rev Med Microbiol 4, 231-241.

Pettersson, B. (1997). Direct solid-phase $16 S$ rDNA sequencing: a tool in bacterial phylogeny. PhD thesis, KTH, Stockholm, Sweden.

Ribosomal Database Project RDP-II (1999). Releax 7.0. Michigan State University, East Lansing, MI, USA.

Saitou, N. \& Nei, M. (1987). The neighbor-joining method: a new method for reconstructing phylogenetic trees. Mol Biol Evol 4, 406-425.

von Schmider, F. \& Ottow, J. C. G. (1986). Characterisierung der denitrifizerenden mikroflora in den verschiedenen reinigungsstufen einer biologischen kläranlage. Arch Hydrobiol 106, 497-512.

Smith, S. (1992). GDE: Genetic data environment, version 2.2. Millipore Imaging Systems, Ann Arbor, MI.

SNV (Svenska Naturvårdsverket; Swedish Agency for Environmental Protection) (1997). Kväve från land till hav. SNV Rapport 4735.

Stackebrandt, E. \& Goebel, B. M. (1994). Taxonomic note: a place for DNA-DNA reassociation and 16S rRNA sequence analysis in the present species definition in bacteriology. Int $J$ Syst Bacteriol 44, 846-849.

Sudesh, K., Toshiaki, F. \& Doi, Y. (1998). Genetic analysis of Comamonas acidovorans polyhydroxyalkanoate synthase and factors affecting the incorporation of 4-hydroxybutyrate monomer. Appl Environ Microbiol 64, 3437-3443.

Watanabe, K., Teramoto, M. \& Harayama, S. (1999). An outbreak of nonflocculating catabolic populations caused the breakdown of a phenol-digesting activated-sludge process. Appl Environ Microbiol 65, 2813-2819.

Wen, A., Fegan, M., Hayward, C., Chakraborty, S. \& Sly, L. I. (1999). Phylogenetic relationships among members of the Comamonadaceae, and description of Delftia acidovorans (den Dooren de Jong 1926 and Tamaoka et al., 1987) gen. nov., comb. nov. Int J Syst Bacteriol 49, 567-576.

Willems, A., Pot, B., Falsen, E., Vandamme, P., Gillis, M., Kersters, K. \& De Ley, J. (1991). Polyphasic taxonomic study of the emended genus Comamonas: relationship to Aquaspirillum aquaticum, E. Falsen group 10, and other clinical isolates. Int $J$ Syst Bacteriol 41, 427-444.

Wilson, K. (1987). Preparation of genomic DNA from bacteria. In Current Protocols in Molecular Biology, pp. 2.4.1.-2.4.5. Edited by F. M. Ausubel, R. Brent, R. E. Kingston, D. D. Moore, J. G. Seidman, J. A. Smith \& K. Struhl. New York: Wiley.

Zumft, W. G. (1997). Cell biology and molecular basis of denitrification. Microbiol Mol Biol Rev 61, 533-616. 